\section{Root Growth of Seedlings and Microcuttings of Western Black Cherry Grown in Compacted Soil}

\author{
Venu G. Oddiraju ${ }^{1}$ and Caula A. Beyl ${ }^{2}$ \\ Department of Plant and Soil Science, Alabama A\&M University, Normal, \\ AL 35762 \\ Philip A. Barker ${ }^{3}$ \\ Urban ForestryResearch, Pacific Southwest Research Station, U.S. Department \\ of Agriculture Forest Service, Berkeley, CA
}

Additional index words. root quantification, digitization, image processing, image analysis, Prunus serotina

\begin{abstract}
Seedlings and microcuttings taken from two western black cherry (Prunus serotina var. virens Ehrh.) trees, one with profuse roots and one with scant roots, were grown in either normal or compacted soil to determine if the variation in the growth of fine and coarse roots under conditions of compaction could be attributed to genetic factors or method of propagation. An image processing system [Image Capture and Analysis System (ICAS)] was used to classify and measure the roots. There was a significant reduction in the surface area of fine roots, total surface area, and root dry weight after 12 weeks of compaction, but the effect on coarse roots was nonsignificant. Initial differences in the larger surface area of coarse roots of seedlings vs. for those of microcuttings disappeared over the course of the experiment. However, the surface areas of fine roots and the total surface area were significantly larger and root dry weight was higher for seedlings than for microcuttings, even at the end of the 12-week treatment period. The surface areas of fine and coarse roots, total surface area, and dry weight of roots were similar at the end of the experiment, regardless of genotype.
\end{abstract}

Although there have been numerous field studies and review articles published concerning root growth and development of forest tree seedlings (Kozlowski, 1971; Perry, 1981), few studies have focused on the differences in root systems as a function of means of propagation or clonal selection for particular root characteristics. Those who have compared vegetative propagules (mainly rooted cuttings) to seedlings have shown developmental and growth differences to be fairly common in some conifers (Hood and Libby, 1978). Vegetative propagules of loblolly pine (Pinus taeda L.) exhibited a tendency for the root system to be dominated by one or a few poorly branched primary roots. Seedlings tended to have numerous lateral roots emerging from the taproot to form a well-branched fibrous root system, whereas rooted cuttings tended to have

Received for publication 17 July 1995 . Accepted for publication 15 Dec. 1995. Contributed by the Agricultural Experiment Station, Alabama A\&M Univ., Journal no. 306. Funding for this research was provided in part by USDA/USFS Cooperative Agreement \#PSW-89-0025CA. We express our appreciation to the late Charles A. Stutte for his time and generosity in allowing us to use Image Capture and Analysis System. The cost of publishing this paper was defrayed in part by the payment of page charges. Under postal regulations, this paper therefore must be hereby marked advertisement solely to indicate this fact.

${ }^{1}$ Graduate Research Assistant.

${ }^{2}$ Professor of Horticulture.

${ }^{3}$ Research Horticulturist (retired). roots that were thicker and more brittle (Brix and Van den Driessche, 1977).

Barker (1990) tested root constraints on container-grown seedlings of western black cherry (Prunus serotina var. virens Ehrh.) using four treatments (35- or 70-cm-deep rootballs, with or without a rootball casing). Along with finding that the mean root weight in treatments with constraints was one-tenth that of treatments without constraints, he also found a wide variation in the mean root weight, ranging from 20 to $1000 \mathrm{~g}$ in treatments without rootball casings, suggesting that there might be a genetic component to root development.

Most studies of root absorption capacity are still based only on root dry weight measurements (Chapin, 1980) because they are easier to obtain than surface area, but root dry weight may not actually reflect the volume of soil explored by the roots. McKeand and Allen (1984), in their study on nutritional and root development factors affecting growth of tissue-cultured plantlets of loblolly pine, found a difference in the relationship between nutrient uptake based on root dry weights as compared to uptake based on root surface area. This result emphasized the need to quantify root systems accurately when studying nutrient uptake. Bowen (1969) and Reid and Bowen (1979) stressed the need to study root morphology. Direct image analysis has been used to quantify elusive root growth phenomena for maple (Acer rubrum L. 'Red Sunset') microcuttings inserted into three rooting media without either disturbing the rooting environment or destroying the plant (Smith et al.,
1990). To overcome the problem of quantifying root systems accurately, the Image Capture and Analysis System (ICAS), which includes many features for image analysis, such as instantaneous viewing and digital image capture, was used to quantify roots in our study (Stutte and Stutte, 1988).

The decline in forest site productivity after the use of heavy equipment is often linked to soil compaction. Compaction is also common in urban sites after heavy equipment use during construction and near pedestrian paths with heavy foot traffic. The objectives of our research were to compare fine and coarse root development under compacted soil treatment of western black cherry seedlings and microcuttings of two lines, one from a tree characterized as having a profuse and the other a scant root system.

\section{Materials and Methods}

Seedlings and microcuttings. Seeds and buds were obtained from two trees of western black cherry that had been used in Barker's (1990) experiment. Seeds or microcuttings obtained from the tree with profuse root development are referred to as line one, profuse roots ( $1 \mathrm{pr})$, and those obtained from the scantrooted tree are referred to as line two, scant roots $(2 \mathrm{sr})$

After the flesh was removed, the seeds were stratified for 4 months at $4 \mathrm{C}$ in moist sphagnum moss and then germinated in plastic bedding containers $(3.75 \times 3.75 \times 5.9 \mathrm{~cm})$ containing Promix BX (Premier Bands, Stamford, Conn.). Four weeks later, they were transferred into the same growing medium in 1.5-liter plastic pots. The plants were then placed in the greenhouse for 14 weeks before they were moved to the field.

Buds from dormant, first-year wood of the selected trees were sterilized following the procedure outlined by Tricoli et al. (1985). Following the procedure detailed by Oddiraju et al. (1994), explants were established on initiation medium, then transferred to a multiplication medium to foster additional shoot proliferation. Shoots were usually ready for subculturing every 4 to 6 weeks. It took $\approx 10$ months to generate the number of shoots required for the experiment. Shoots from multiplication medium were encouraged to elongate further by transferring them to a medium containing no hormones.

When the shoots had elongated to $\approx 5 \mathrm{~cm}$, they were cut and dipped in Hormex powder [1.6\% $1 H$-indole-3-butanoic acid (IBA); Brooker Chemical, Hollywood, Calif.] before they were moved into flats $(52.5 \times 26.25 \times$ $6.25 \mathrm{~cm})$ containing starter pots $(3.75 \times 3.75 \times$ $5.9 \mathrm{~cm})$. The growth medium used, Promix $\mathrm{BX}$, had been autoclaved and drenched well with 3a,4,7,7a-tetrahydro-2-[(trichloromethyl) thiol]- $1 H$-isoindole-1,3(2H)-dione (captan; Microflo, Lakeland, Fla.) at 3.75 g.liter ${ }^{-1}$ before the shoots were transferred under a sterile transfer hood into the flats. The procedure used for acclimatizing the rooted shoots was the same used by Oddiraju et al. (1994). Two weeks after the 4-week acclimatization pe- 
riod, the plants were moved into 1.5-liter plastic pots containing Promix BX and allowed to grow for 12 weeks to equalize initial sizes of the two lines, seedlings and microcuttings, as much as possible. Plants were $\approx 15$ to $20 \mathrm{~cm}$ tall, except for one treatment group (microcuttings of 1pr), which still lagged behind the others and was only $\approx 10 \mathrm{~cm}$ tall, primarily due to its poor performance in the in vitro environment.

Field preparation. The site for this experiment was located on the Agricultural Research Farm on the campus of Alabama A\&M Univ., Normal. The soil on the site was a Decatur silt loam. The land was plowed, then disked twice in two directions to eliminate weeds and level the surface in preparation for the compaction treatments. There were four replications of the two treatments (compacted vs. control). Compaction was achieved by rolling a 290-kg lawn roller over the plots 100 times. Soil bulk densities were then measured using a CN-940 Eley volumeter (Soil Test, Lake Bluff, Ill.). The compacted soil had a bulk density of $1.2 \mathrm{~g} \cdot \mathrm{cm}^{-3}$ at the surface and 1.06 at a depth of $15 \mathrm{~cm}$. Soil in the control plots had a bulk density of $0.95 \mathrm{~g} \cdot \mathrm{cm}^{-3}$ at the surface and 0.94 at a depth of $15 \mathrm{~cm}$. A hole just large enough to accommodate the root system was dug when plants were placed in the field to minimize disturbing the compaction zone as much as possible. Plants were thoroughly hand-irrigated once every 2 days.

Before seedlings and microcuttings were moved to the field, one plant of each treatment and replication was analyzed to determine the initial, pretreatment coarse and fine root surface areas, root dry weights, leaf areas and dry weights. Seedlings and microcuttings were 18 weeks old when they were moved to the field on 18 June 1991. The initial means were subtracted from the final values to obtain relative growth rates for the different treatments. Final values of fine and coarse root surface area, root and leaf dry weights, and leaf areas were obtained from plants in the field after they had been growing under compacted and control conditions for 12 weeks. Total root surface area, coarse : fine root ratio, shoot : root ratio (shoot dry weight/root dry weight), and specific root weight (root dry weight/root surface area) were calculated from the measured root surface areas, and the root and shoot dry weights.

This experiment was arranged as a split plot and replicated four times with compaction as the main plot, and method of propagation (seedlings vs. microcuttings) and line (1pr and 2sr) as split treatments arranged factorially with three subsamples in each treatment combination. One single-tree subsample was used to obtain initial data and the remaining two subsamples were used to obtain final data. Data were subjected to analysis of variance (ANOVA). Tukey's HSD $(P \leq 0.05)$ was used to separate means of only main treatment effects and interactions that were significant in the ANOVA.

Root surface area measurements. Rootballs were excavated to a $30-\mathrm{cm}$ radius around the base of the plant, and roots were carefully separated from the adhering soil by gentle washing before their surface areas were measured. ICAS (Digital Image Acquisition Systems, Englewood, Colo.) was used to classify the roots as fine or coarse and measure the surface area of the roots (Oddiraju et al., 1994). Digitized images were saved on floppy disks for further analysis. Following digitization, background intensities were deleted and an eight-level classification was performed. Reflected light intensities allowed interpretation of classes 1 and 2 as background; classes 3, 4, and 5 as coarse roots; and classes 6,7 , and 8 as fine roots.

\section{Results and Discussion}

Initial measurements. ANOVA of the data collected just before the plants were placed under the two degrees of compaction showed a highly significant $(P \leq 0.01)$ difference between seedlings and microcuttings with respect to coarse root surface area, fine root surface area, and root dry weight (Fig. 1). Early differences between seedlings and microcuttings also have been reported by Leach (1979) and McKeand and Wisniewski (1982). These differences were attributed to the time required by the microcuttings to become acclimated to greenhouse conditions and establish themselves in the field. Environmental conditions under which tissue-cultured plantlets develop are characterized by high relative humidity, almost no air movement, low light levels, and a heterotrophic mode of nutrition. The field and greenhouse are characterized by lower rates of humidity, variable wind speeds, higher light levels, and a shift to autotrophic nutrition (Conner and Thomas, 1981). As a result, plantlets experience severe stress when
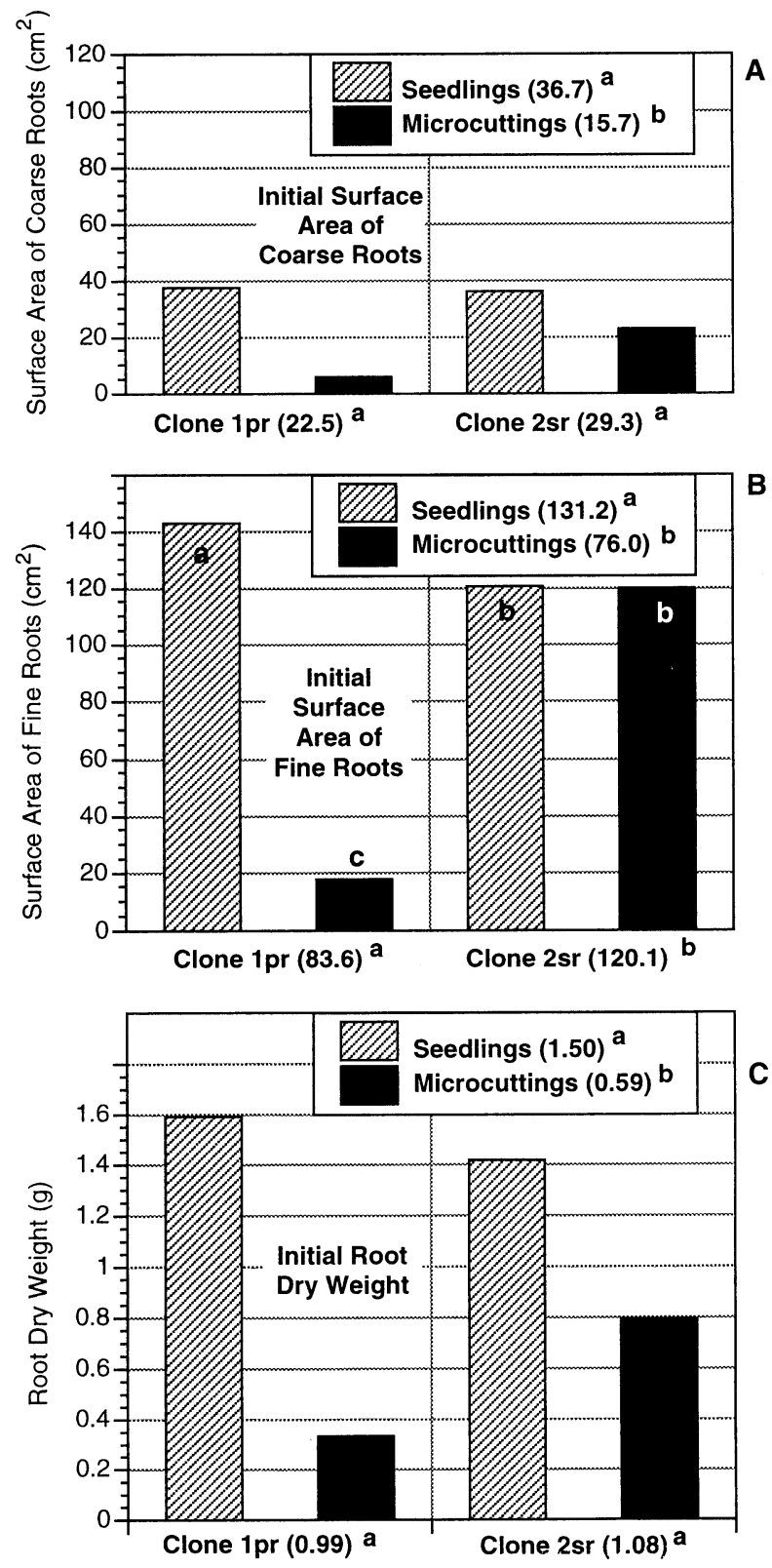

Fig. 1. Initial measurements of western black cherry seedlings and microcuttings for (A) surface area of coarse roots, (B) surface area of fine roots, and $(\mathbf{C})$ dry weight of roots. The numbers in parentheses represent main treatment means. Mean separation by Tukey's HSD $(P \leq 0.05)$. 
moved from the tissue culture environment to greenhouse or field conditions. Plantlets typically become water-stressed, and continued growth or survival may be threatened (Sutter and Langhans, 1982). Many roots formed in vitro may die after transplanting (McClelland et al., 1990).

Initial surface area of coarse roots (Fig. 1A) was significantly higher in seedlings than in microcuttings in both lines. The mean surface area of coarse roots for seedlings was 37 vs. $16 \mathrm{~cm}^{2}$ for microcuttings (Fig. 1A). This feature also was observed in vegetative propagules of loblolly pine (Pinus taeda L.), which exhibited a tendency for the root system to be dominated by one or a few poorly branched primary roots (McKeand and Wisniewski, 1982). At the age of 6 weeks, loblolly pine seedlings in the above study had 10 times more lateral roots compared to plantlets.

The initial mean surface area of fine roots for seedlings was 131 vs. $76 \mathrm{~cm}^{2}$ for microcuttings (Fig. 1B), and root dry weight was 1.50 for seedlings vs. $0.59 \mathrm{~g}$ for microcuttings (Fig. 1C). There was a significant effect of line only on fine root surface area, with $1 \mathrm{pr}$ having a mean fine root surface area of 84 vs. $120 \mathrm{~cm}^{2}$ (Fig. 1B) for 2sr. There also was a highly significant interaction between line and method of propagation due to the large size difference between 1 pr seedlings and microcuttings. We attributed this difference to the small size of $1 \mathrm{pr}$ microcuttings at the start of the experiment. The poor growth of line $1 \mathrm{pr}$ (from a tree selection characterized by many roots) under tissue culture conditions has been reported previously (Oddiraju et al., 1994). Its poor performance compared to $2 \mathrm{sr}$ (from a tree selection characterized by scant roots) also was reflected in all the other attributes measured. In spite of this disparity of initial size, $1 \mathrm{pr}$ microcuttings were included because relative growth information could still be obtained.

Initial leaf area and leaf dry weight measurements were not significantly different for the two lines or methods of propagation (data not shown).

Final observations. By the final observations at the end of the 12 weeks of treatment, compaction significantly had reduced the surface area of fine roots (Fig. 2A) and root dry weight (Fig. 3A), but the reduction of total root surface area (Fig. 2B) was nonsignificant $(P=$ $0.07)$. There was no significant effect of compaction on surface area of coarse roots (data not shown) or shoot : root ratio (Fig. 3B).

The initial differences in surface area of fine roots and root dry weight between seedlings and microcuttings persisted until the end of the experiment 12 weeks later (Figs. 2A and $3 \mathrm{~A})$. Seedlings had a mean fine root surface area of 141 vs. $94 \mathrm{~cm}^{2}$ for microcuttings (Fig. 2A) and a root dry weight of $2.9 \mathrm{vs} .1 .7 \mathrm{~g}$ (Fig. 3A). Seedlings had more finer, branched roots than coarse roots. However, seedlings and microcuttings did not differ in surface area of coarse roots by the time of the final measurements. These results are similar to those of McKeand and Wisniewski (1982), who reported that, compared to plantlets, seedlings
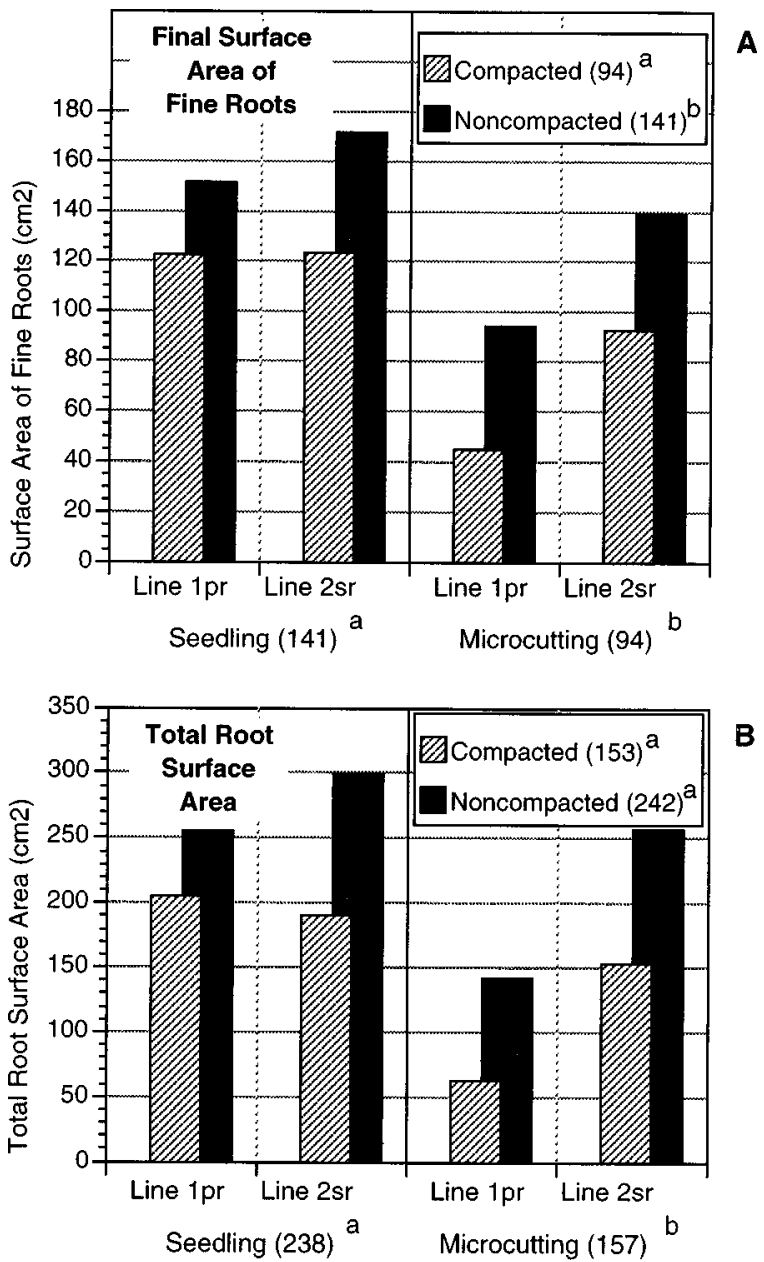

Fig. 2. Final measurements of western black cherry seedlings and microcuttings after 12 weeks of growth in noncompacted or compacted soil for $(\mathbf{A})$ surface area of fine roots and $(\mathbf{B})$ total surface area of roots. The numbers in parentheses represent main treatment means. Mean separation by Tukey's HSD $(P \leq$ $0.05)$.

had more laterals even at the age of 20 weeks. Brix and Van den Driessche (1977) also reported similar results from their work on pines.

Shoot : root ratio was significantly higher for microcuttings (2.7) than for seedlings (1.5) (Fig. 3B). No significant differences existed among any treatments with respect to leaf areas and dry weights. Perhaps if the time interval under compaction treatment had been longer, then significant differences in shoot growth might have occurred. Differences also were nonsignificant for coarse : fine root ratios and specific root weights.

Relative growth. Compaction had a significant effect on the relative growth of fine roots (final - initial surface area of fine roots; Fig. 4A), relative total root surface area (Fig. 4B), and relative increase in root dry weight (Fig. 4C), but had no effect on surface area of coarse roots. The increase in surface area of fine roots in noncompacted soil $\left(31 \mathrm{~cm}^{2}\right)$ was significantly higher compared to the increase in surface area in compacted soil $\left(5.5 \mathrm{~cm}^{2} ;\right.$ Fig. 3A). Simmons and Pope (1987) reported similar results from their study on sweetgum ( $\mathrm{Liq}$ uidambar styraciflua L.) and yellow poplar (Liriodendron tulipifera L.) roots. Root systems of sweetgum, which are very fine and highly branched (fibrous), were significantly reduced as bulk density increased from 1.25 to $1.40 \mathrm{mg} \cdot \mathrm{m}^{-3}$. However, in yellow poplar, with its coarse and less-branched root system, fibrosity of the roots was not significantly affected by increasing bulk density. These results indicate that the response of plant roots to compaction depends on the morphological characteristics of their root system.

There was a reduction in fine root surface area of line $2 \mathrm{sr}$ microcuttings relative to the initial values, which probably indicated that roots initially measured as fine had enlarged enough to be classified as coarse by the end of the experiment or that fine roots had died. Reduced values for relative total root surface area for line 2 sr compacted microcuttings and for relative dry weight of line 2 sr compacted seedlings relative to initial values may indicate a higher sensitivity of line 2 sr to compaction. There also was a significant interaction between line and method of propagation for the relative increase in surface area of fine roots. Microcuttings of line $1 \mathrm{pr}$ had a significantly higher growth rate than line $1 \mathrm{pr}$ seedlings or line 2 sr microcuttings (Fig. 4A). Possibly, the field conditions suited $1 \mathrm{pr}$ microcuttings better than the in vitro environment in which its growth was very slow. This effect could also have been due to the fact that 

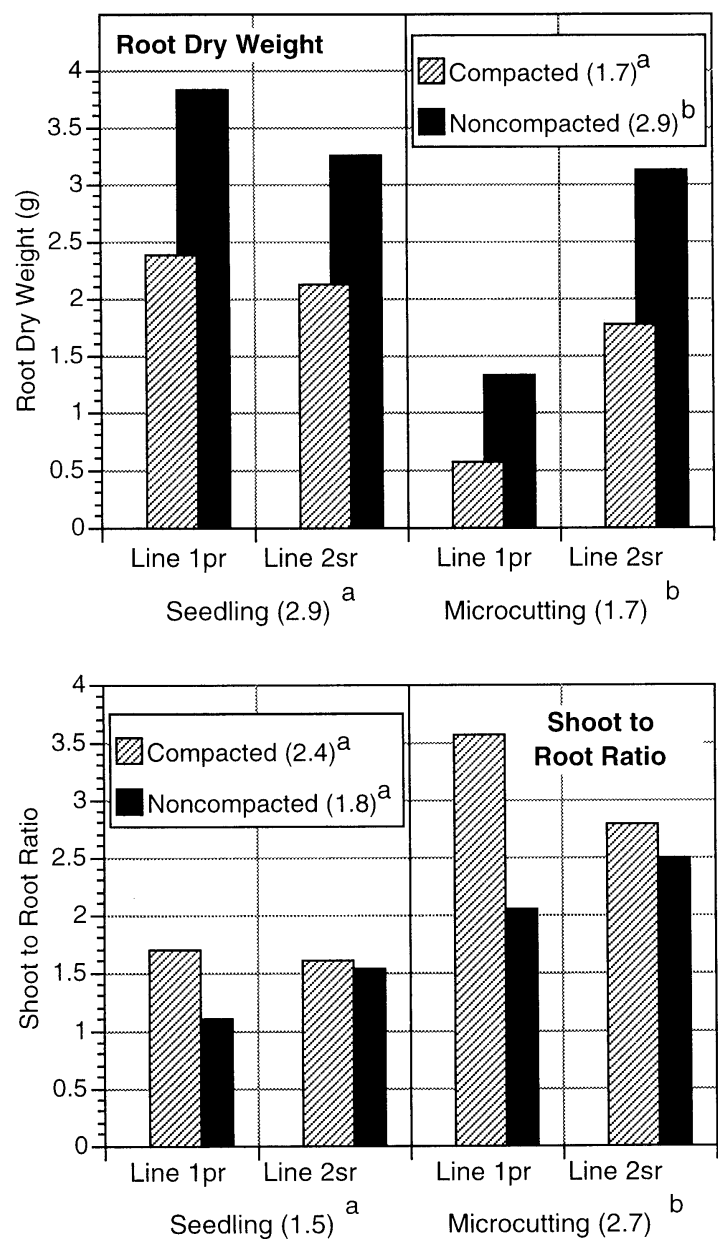

Fig. 3. Final measurements of western black cherry seedlings and microcuttings after 12 weeks of growth in noncompacted or compacted soil for (A) final root dry weight and (B) shoot : root ratio. The numbers in parentheses represent main treatment means. Mean separation by Tukey's HSD $(P \leq 0.05)$.

smaller microcuttings of line $1 \mathrm{pr}$ adapted to field conditions more quickly, whereas the others experienced more transplant stress.

There was no significant effect of line, compaction, or method of propagation on relative coarse root surface area (data not shown), but there was a significant effect of compaction on relative total root surface area (Fig. 4B). The relative total root surface area was 24 $\mathrm{cm}^{2}$ for plants in compacted treatments and $116 \mathrm{~cm}^{2}$ for those in the noncompacted. Line 2sr noncompacted seedlings (Fig. 4B) had the largest total root surface area. Under compaction, line 2 sr seedlings and microcuttings also exhibited the least increase in total root surface area. Although line 2 sr was very sensitive to compaction, this effect of genotype was not enough to give a significant line effect for relative total root surface area. The relative increase in the dry weight of roots (Fig. 4C) also was significantly lower for plants under compacted $(0.46 \mathrm{~g})$ than noncompacted soil (1.99 g).

Although the values were higher for seedlings than for microcuttings (Figs. 4A-C), there was no significant effect of method of propagation on any of the relative measurements, including fine, coarse, and total root surface area, or root dry weight.

Overall, compaction had a greater effect in
A

B

restricting the surface area of fine roots and root dry weight of western black cherry plants than on their surface area of coarse roots. This differential effect on finer roots could have been due to disproportionate death or turnover of smaller absorption roots. The effect on finer roots may also negatively impact the overall effectiveness of the root system and be a contributing factor in the death of trees under prolonged compaction stress. In this experiroots between seedlings and microcuttings of western black cherry trees can be seen when they are only 30 weeks old. Root characteristics of the line parent tree (profuse or scant root development) are probably not genetic since these characteristics were absent in the two lines of western black cherry we used.

\section{Literature Cited}

Barker, P.A. 1990. Tree root and sidewalk conflicts, p. 134-136. In: P.D. Rodbell (ed.). Make our cities safe for trees. Proc. Fourth Urban For. Conf., 15-19 Oct. 1989, St. Louis. Amer. For. Assn., Washington, D.C.

Bowen, G.D. 1969. The uptake of orthophosphate and its incorporation into organic phosphates along roots of Pinus radiata. Aust. J. Biol. Sci. 22:1125-1135.

Brix, H. and R. Van den Driessche. 1977. Use of ment, differences in the surface area of fine

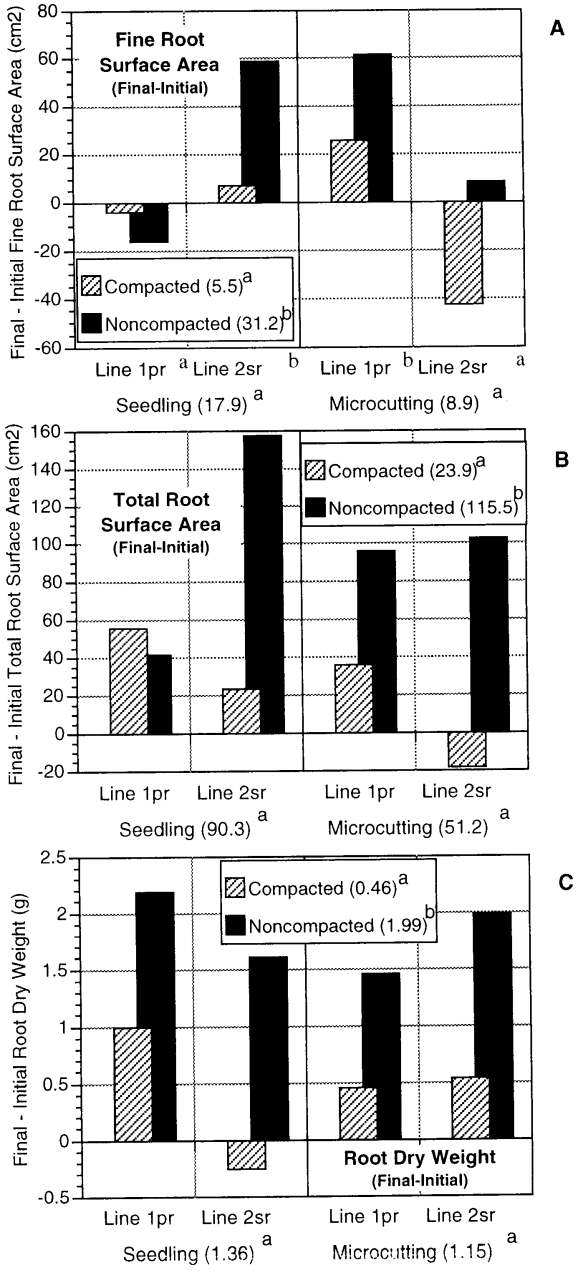

Fig. 4. Relative change (final - initial) of western black cherry seedlings and microcuttings grown in noncompacted or compacted soil for (A) fine root surface area, (B) total root surface area, and (C) root dry weight. The numbers in parentheses represent main treatment means. Mean separation by Tukey's HSD $(P \leq 0.05)$.

rooted cuttings in reforestation- $\mathrm{A}$ review of opportunities, problems and activities. British Columbia For. Service/Can. For. Serv. Joint Rpt. 6.

Chapin, F.S. III. 1980. The mineral nutrition of wild plants. Ann. Rev. Ecol. Syst. 11:233-260.

Conner, A.J. and M.B. Thomas. 1981. Re-establishing plantlets from tissue culture: A review. Intl. Plant Prop. Soc. Comb. Proc. 28:342-357.

Hood, J.V. and W.J. Libby. 1978. Continuing effects of maturation state in radiata pine and a general maturation model. In: Propagation of higher plants through tissue culture. A bridge between research and application. Proc. Intl. Symp. p. 220-232.

Kozlowski, T.T. 1971. Growth and development of trees. vol. II. Academic, New York.

Leach, G.N. 1979. Growth in soil of plantlets produced by tissue culture. Tech. Assn. Pulp \& Paper Industries 62:59-61.

McClelland, M.T., M.A.L. Smith, and Z.B. Carothers. 1990. The effects of in vitro and ex vitro root initiation on subsequent microcutting root quality in three woody plants. Plant Cell, Tissue \& Organ Culture 23:115-123.

McKeand, S.E. and H.L. Allen. 1984. Nutritional and root development factors affecting growth of tissue culture plantlets of loblolly pine. Physiol. Plant. 61:523-528.

HortScience, Vol. 31(3), June 1996 
McKeand, S.E. and L.A. Wisniewski. 1982. Root morphology of loblolly pine tissue culture plantlets. Proc. 7th North Amer. For. Biol. Workshop, Lexington, Ky. p. 214-219.

Oddiraju, V.G., C.A. Beyl, P.A. Barker, and G.W Stutte. 1994. Container size alters root growth o western black cherry as measured via image analysis. HortScience 29:910-913.

Perry, T.O. 1981. Tree roots-Where they grow: Implications and practical significance. In: New horizons from the Horticultural Research Institute. p. $39-48$.

Reid, C.P.P. and G.D. Bowen. 1979. Effects of water stress on phosphorus uptake by mycorrhizas of Pinus radiata. New Phytol. 83:103-107.

Simmons, G.L. and P.E. Pope. 1987. Influence of soil compaction and vesicular-arbuscular mycorrhizae on root growth of yellow poplar and sweetgum seedlings. Can. J. For. Res. 17:970 975

Smith, M.A.L., L.A. Spomer, and M.T. McClelland. 1990. Direct analysis of root zone data in a microculture system. Plant, Cell, Tissue \& Organ Culture 23:21-26.

Stutte, C.A. and G.W. Stutte. 1988. An interactive image capture and analysis system (ICAS) for research and crop management, p. 151-159. In: P. Mausel (ed.). Videography: First workshop. Amer. Soc. Photogrammetry and Remote Sensing, Terre Haute, Ind.

Sutter, E.G. and R.W. Langhans. 1982. Formation of epicuticular wax and its effects on water loss in cabbage plants regenerated from shoot-tip culture. Can. J. Bot. 60:2896-2902.

Tricoli, D.M., C.A. Maynard, and A.P. Drew. 1985 Tissue culture propagation of mature trees of Prunus serotina Ehrh. I. Establishment, multiplication and rooting in vitro. For. Sci. 31:201208. 